\title{
PENGEMBANGAN MULTIMEDIA INTERAKTIF PADA PEMBELAJARAN TEMATIK INDAHNYA NEGERIKU UNTUK SISWA KELAS IV SEKOLAH DASAR
}

\author{
Kuncahyono, Sudarmiatin \\ Universitas Negeri Malang, Jalan Semarang 5 Malang 65145 \\ E-mail: kuncahyono@ymail.com
}

\begin{abstract}
The objective of this research and development was to produce interactive multimedia product of thematic which valid, practical, effective, and interesting. The development research model used is the ASSURE model, namely: (1) analysis of student characteristics; (2) determine learning objectives; (3) choosing strategy, technology, media and material; (4) using technology, media and materials; (5) requires student participation; and (6) assessing and revising. The results showed that interactive multimedia products were declared valid. The results of the $87.15 \%$ field test match the practicality criteria. Attractiveness gets $92.6 \%$ (interesting). Based on paired $t$ test, thematic interactive multimedia the beauty of my country is effectively used in learning because it can improve student learning outcomes.
\end{abstract}

Keywords: interactive multimedia; thematic learning; elementary students

\begin{abstract}
Abstrak: Tujuan penelitian dan pengembangan ini adalah menghasilkan produk multimedia interaktif tematik yang valid, praktis, efektif, dan menarik. Model penelitian pengembangan yang digunakan adalah model ASSURE yaitu: (1) analisis karakteristik siswa; (2) menentukan tujuan pembelajaran; (3) memilih strategi, teknologi, media, dan materi; (4) menggunakan teknologi, media, dan materi; (5) memerlukan partisipasi siswa; dan (6) menilai dan merevisi. Hasil penelitian menunjukkan bahwa produk multimedia interaktif dinyatakan valid. Hasil uji coba lapangan $87,15 \%$ sesuai dengan kriteria kepraktisan. Kemenarikan memperoleh hasil 92,6\% (menarik). Berdasarkan uji t berpasangan, multimedia interaktif tematik indahnya negeriku efektif digunakan dalam pembelajaran karena dapat meningkatkan hasil belajar siswa.
\end{abstract}

Kata kunci: multimedia interaktif; pembelajaran tematik; siswa sekolah dasar

Perkembangan alat-alat teknologi informasi dan komunikasi ditandai dengan bermunculan peralatan-peralatan seperti handphone, komputer, dan laptop. Peralatan teknologi tersebut banyak dimanfaatkanolehparapraktisipendidikanterutama guru untuk meningkatkan kualitas pembelajaran. Salah satu contoh adanya pemanfaatan fasilitas pembelajaran berbasis teknologi adalah sebagai alat bantu dalam pembelajaran. Alat bantu yang dimaksud dapat berupa media komputer atau laptop, teknologi jaringan internet e-learning, dan teknologi Liquid Crystal Display (LCD) Proyektor. Perkembangan teknologi juga menjadi salah satu faktor pengembangan kurikulum yang berlaku saat ini yaitu Kurikulum 2013. Salah satu yang dapat disoroti dari Kurikulum 2013 ini adalah pelaksanaan pembelajaran tematik. Pembelajaran tematik merupakan pendekatan pembelajaran yang mengintegrasikan berbagai kompetensi dari berbagai mata pelajaran (Prastowo, 2013; Gunawan \& Sulistyoningrum, 2013). Pembelajaran tematik terpadu menggunakan salah satu model pembelajaran terpadu model jaring laba-laba (webbed model). Model ini berangkat dari pendekatan tematis sebagai acuan dasar bahan dan kegiatan pembelajaran (Kusumaningrum, Arifin, \& Gunawan, 2013)(Fogarty, 1991; Mursidik, et al., 2013; Gunawan, 2018).

Studi pendahuluan telah dilakukan untuk mengungkap keberadaan sarana teknologi di SDN Model Kota Malang. Diketahui bahwa di SDN Model Kota Malang memiliki laboratorium 
komputer lengkap dengan peralatan komputer, ruang kelas yang dilengkapi dengan sarana LCD Proyektor. Fasilitas laboratorium komputer yang ada di SDN Model Kota Malang belum dimanfaatkan oleh para guru untuk menunjang pembelajaran selain guru komputer. Hal ini perlu mendapat perhatian karena fasilitas belum dimanfaatkan secara optimal. Informasi awal juga diperoleh dari angket kepada siswa Kelas IV-B. Hasil angket menunjukkan bahwa siswa belum pernah belajar tematik menggunakan multimedia, nilai siswa cenderung kurang baik dalam pembelajaran tematik, siswa senang belajar dengan memanfaatkan media komputer dan LCD proyektor. Siswa juga tertarik dengan pembelajaran yang ada gambar dan permainan. Hal ini tentunya perlu diperhatikan agar pembelajaran tematik bagi siswa menjadi menyenangkan sesuai dengan Peraturan Pemerintah Nomor 32 Tahun 2013 tentang Perubahan atas Peraturan Pemerintah Nomor 19 Tahun 2005 tentang Standar Nasional Pendidikan yang mengamanatkan proses pembelajaran pada suatu pendidikan diselenggarakan secara interaktif, inspiratif, menyenangkan, menantang, memotivasi peserta didik untuk berpartisipasi aktif.

Hasil observasi dan wawancara yang dilakukan selanjutnya menunjukkan bahwa: (1) pembelajaran tematik di kelas IVB cenderung bersifat konvensional yaitu guru menggunakan metode ceramah dan tanya jawab; (2) guru kurang maksimal menggunakan dan memanfaatkan media yang ada; (3) guru menggunakan buku teks tematik terpadu terbitan pemerintah; (4) guru belum pernah membuat dan menggunakan multimedia interaktif tematik; (5) Siswa kurang semangat dalam belajar tematik karena sulit menjawab soal latihan dan materi di buku siswa sedikit; dan (6) peran guru lebih dominan dalam mengajar (teacher centered). Strategi seperti ini kurang memenuhi prinsip pembelajaran efektif dalam memberdayakan potensi siswa. Aspek pembelajaran efektif adalah peningkatan pengetahuan, keterampilan, perubahan sikap, perilaku, kemampuan adaptasi, peningkatan integritas, partisipasi, dan interaksi kultural (Daryanto, 2012; Gunawan, et al., 2008).

Adanya kesenjangan kondisi nyata dengan kondisi ideal jika tidak ditindaklanjuti, dikhawatirkan dapat berdampak pada hasil belajar, motivasi, dan minat siswa. Salah satu alternatif untuk mengurangi pola pembelajaran teacher centered dan memaksimalkan sarana teknologi yang ada adalah guru tidak hanya mengandalkan buku pegangan dalam mengajar, tetapi dapat melengkapi dengan media pembelajaran berbasis teknologi. Siswa dapat memanfaatkan teknologi dan media untuk meningkatkan kualitas belajarnya (Smaldino, 2011). Berdasarkan fenomena yang telah dipaparkan, baik guru maupun siswa Kelas IV-B memerlukan suatu inovasi dalam pembelajaran tematik, terutama inovasi penggunaan media pembelajaran yaitu multimedia interaktif yang mengacu pada Kurikulum 2013.

Penelitian ini difokuskan pada satu sekolah dasar yang menerapkan Kurikulum 2013 yaitu SDN Model Kota Malang sebagai pilot project. Materi yang dikembangkan melalui multimedia interaktif khusus untuk subtema keindahan alam negeriku. Alasan pemilihan subtema tersebut karena: (1) materi dan gambar dalam subtema keindahan alam negeriku di buku tematik cenderung terbatas dan kurang lengkap; (2) materi mudah dikembangkan dan sesuai jika disajikan dalam multimedia interaktif; (3) materi perlu tambahan visualisasi video sebagai wujud gambaran konkret agar materi lebih mudah dipahami; dan (4) adanya kesepakatan antara guru kelas dan peneliti dalam pemilihan subtema. Berdasarkan uraian pertimbangan yang sudah dipaparkan, tujuan penelitian ini ialah mengembangkan multimedia interaktif pada pembelajaran tematik indahnya negeriku.

\section{METODE}

Penelitian dan pengembangan untuk mengembangkan produk multimedia interaktif mengguakan model pengembangan ASSURE, meliputi: (1) analyze learner, (2) state standards and objectives; (3) select stategies, technology, media, and materials; (4) utilize technology, media, and materials; (5) require learner participation; dan (6) evaluate and revise (Smaldino, 2011). Desain pada penelitian dan pengembangan ini dilakukan uji validasi ahli materi atau bahan ajar, ahli bahasa, dan ahli media. Selain itu dilakukan uji coba lapangan dengan subjek uji coba guru dan siswa Kelas IV SDN Model Kota Malang. Hasil uji coba ahli digunakan untuk mengetahui kelayakan materi, kebahasaan, dan tampilan multimedia interaktif tematik. Sedangkan uji coba lapangan 
kepada guru dan siswa untuk mengetahui tingkat efektivitas, tingkat kepraktisan, dan kemenarikan produk multimedia interaktif.

Instrumen pengumpulan data yang digunakan pada penelitian dan pengembangan ini berupa angket validasi dan lembar tes. Instrumen berupa angket digunakan untuk menilai validitas produk. Penilaian dilakukan oleh ahli media, ahli bahasa, dan ahli materi/bahan ajar. Angket penilaian untuk menguji kemenarikan dan efektivitas produk diberikan kepada siswa. Instrumen lembar tes sebagai alat pengumpul data nilai hasil belajar siswa sebelum menggunakan multimedia (pre test) dan setelah menggunakan multimedia (post test). Tes hasil belajar diperlukan untuk mendapatkan data tentang efektivitas penggunaan multimedia interaktif tematik. Instrumen post test terintegrasi dalam multimedia interaktif.

Data yang terkumpul selanjutnya dianalisis secara deskriptif kualitatif dan deskriptif kuantitatif. Analisis data deskriptif kualitatif dilakukan dengan cara mengelompokkan informasi dari data yang berupa catatan masukan, saran, tanggapan, dan komentar berdasarkan hasil penilaian/ujicoba. Analisis data deskriptif kuantitatif dilakukan terhadap data yang diperoleh melalui angket validasi ahli materi, ahli bahasa, ahli media, dan lembar tes hasil belajar siswa dalam pembelajaran tematik. Hasil penilaian validitas, kepraktisan, dan kemenarikan produk kemudian ditetapkan berdasarkan kriteria tertentu. Uji efektivitas produk multimedia interaktif digunakan desain penelitian eksperimen one group pretest-posttest design (Sugiyono, 2010). Uji dilakukan dengan membandingkan keadaan kelas sebelum dan sesudah menerima perlakuan. Hasil pretest dan posttest kemudian dianalisis menggunakan uji-t berpasangan menggunakan program SPSS PASW Statistics 21. Multimedia dikatakan efektif jika terdapat perbedaan yang signifikan antara nilai prestest dan posttest, multimedia dikatakan tidak efektif jika tidak terdapat perbedaan yang signifikan antara nilai prestest dan posttest.

\section{HASIL}

Penelitian pengembangan ini menghasilkan produk berupa multimedia interaktif pada pembelajaran tematik indahnya negeriku subtema keindahan alam negeriku. Uji coba produk dilakukan melalui lima tahap, yaitu validasi ahli materi tematik, validasi ahli bahasa, validasi ahli media, serta uji keefektifan dan kemenarikan oleh pengguna yaitu guru dan siswa kelas IVB yang terdiri atas 20 siswa. Hasil uji validasi dinyatakan atau dinilai valid dan praktis oleh ahli materi, ahli bahasa, dan ahli media. Hasil uji lapangan oleh pengguna diperoleh simpulan bahwa produk yang dikembangkan tergolong efektif dan menarik. Selain itu, penelitian ini juga menghasilkan produk berupa buku pedoman penggunaan multimedia untuk guru dan siswa yang dilengkapi dengan Rencana Pelaksanaan Pembelakaran (RPP). Dengan demikian produk yang dihasilkan ini dapat digunakan dalam pembelajaran subtema keindahan alam negeriku. Berikut ini cuplikan produk dan disajikan dalam bentuk print screen hasil produk pengembangan multimedia interaktif indahnya negeriku (Gambar 1 s.d. 6).

Berdasarkan hasil uji coba ahli (materi, bahasa, media), dan uji coba pengguna di lapangan (guru dan siswa) dapat dikatakan bahwa multimedia interaktif tematik indahnya negeriku valid, praktis, efektif, dan menarik. Secara eksplisit rekapitulasi hasil validasi ahli materi, bahasa dan media dapat dilihat pada Tabel 1. Berdasarkan Tabel 1 didapatkan hasil validitas media dari aspek materi memperoleh persentase $88 \%$ dikategorikan valid dan dapat digunakan dengan revisi kecil. Produk dari aspek bahasa memperoleh kesesuaian dengan kriteria sebesar 82,5\% sehingga dikategorikan valid, atau boleh digunakan namun dengan revisi kecil. Selanjutnya berdasarkan data dari ahli media diperoleh kesesuaian sebesar $74 \%$ sehingga dikategorikan valid, atau boleh digunakan namun dengan revisi kecil. Komentar dari ahli materi yaitu perlu menambahkan teks petualangan dalam materi multimedia, langkah-langkah pendekatan saintifik lebih diperjelas dalam RPP, dan siswa perlu melakukan percobaan setelah melihat animasi dalam multimedia agar pembelajaran menjadi bermakna. Komentar dan saran dari ahli bahasa yaitu multimedia secara umum sudah bagus tetapi perlu mengurangi penggunaan kalimat yang terlalu panjang agar siswa lebih mudah memahami. Komentar dari ahli media secara umum diantaranya agar tampilan interface dan tombol lebih teratur agar siswa lebih mudah menggunakannya.

Setelah didapat hasil tingkat validitas materi, bahasa, dan media, selanjutnya 
Tabel 1 Rekapitulasi Hasil Analisis Tingkat Validitas Produk dari Ahli Materi, Bahasa, dan Media

\begin{tabular}{|c|c|c|}
\hline Validator & Hasil & Komentar dan Saran \\
\hline Ahli Materi & $\begin{array}{l}\text { Validasi materi } 88 \% \\
\text { (Valid dan dapat digunakan } \\
\text { dengan revisi kecil) }\end{array}$ & $\begin{array}{l}\text { 1. Perlu dipikirkan lagi untuk menjangkau muatan } \\
\text { bahasa Indonesia yaitu berupa teks petualangan. } \\
\text { 2. Dalam RPP pendekatan saintifik belum secara jelas } \\
\text { terlihat. Usahakan lebih eksplisit. } \\
\text { 3. Aspek psikomotorik dari materi percobaan perlu } \\
\text { dilakukan secara kontekstual yaitu siswa perlu } \\
\text { melakukan percobaan secara langsung tidak sekedar } \\
\text { melihat video/animasi. }\end{array}$ \\
\hline Ahli Bahasa & $\begin{array}{l}\text { Validasi bahasa } 82,5 \% \\
\text { (Valid dan perlu revisi } \\
\text { kecil) }\end{array}$ & $\begin{array}{l}\text { 1. Kalimat-kalimat yang terlalu panjang dipotong saja. } \\
\text { 2. Multimedia secara umum sudah bagus. }\end{array}$ \\
\hline Ahli Media & $\begin{array}{l}\text { Validasi media } 74 \% \text { (Valid } \\
\text { dan perlu revisi kecil) }\end{array}$ & $\begin{array}{l}\text { 1. Secara umum sudah bagus. } \\
\text { 2. Petunjuk penggunaan lebih diperjelas. } \\
\text { 3. Perlu pemakaian tombol yang konsisten agar lebih } \\
\text { beraturan. } \\
\text { 4. Perlu ditingkatkan keterpaduan tombol hyperlink. } \\
\text { 5. Storyboard perlu ditambahkan sinopsis dan } \\
\text { treatment. }\end{array}$ \\
\hline Validator gabungan & $\begin{array}{l}81,5 \% \\
\text { valid atau boleh digunakan } \\
\text { dengan revisi kecil }\end{array}$ & \\
\hline
\end{tabular}

dilakukan perhitungan skor rata-rata dengan cara menjumlahkan dan membagi tiga untuk mengetahui hasil akhir tingkat validitas produk yang dikembangkan. Hasil tingkat validitas produk mencapai persentase $81,5 \%$, artinya produk multimedia interaktif ini masuk dalam kriteria valid atau boleh digunakan dengan revisi kecil. Data kepraktisan multimedia interaktif diperoleh dari guru dan siswa Kelas IV-B SDN Model Kota Malang melalui uji coba lapangan. Secara ekplisit rekapitulasi hasil uji coba lapangan untuk mengukur tingkat kepraktisan, kemenarikan, dan keefektifan produk dapat dilihat pada Tabel 2. Berdasarkan Tabel 2 diperoleh rekapitulasi hasil analisis uji coba produk yang menunjukkan tingkat kepraktisan produk mencapai $87,15 \%$ sesuai kriteria (praktis). Kemenarikan produk mencapai 92,6\% sesuai kriteria (praktis). Selanjutnya keefektifan produk mencapai kriteria efektif karena terdapat perbedaan yang signifikan antara nilai pretest (sebelum menggunakan multimedia) dan postest (sesudah menggunakan multimedia). Oleh karena nilai $\mathrm{t}_{\text {-hitung }}<\mathrm{t}_{\text {-tabel }}(-7.566<-2,093)$ dan $\mathrm{P}$ value $(0,000<0,05)$ maka Ho ditolak dan Ha diterima, artinya terdapat perbedaan yang signifikan antara nilai pretest (sebelum menggunakan produk multimedia) dan postest (sesudah menggunakan produk multimedia).

Berdasarkan hasil t hitung, dapat diketahui $\mathrm{t}$ hitung negatif berarti rata-rata pretest lebih rendah daripada rata-rata postest. Skor rata-rata pretest 74,6 sedangkan skor rata-rata postest 87 . Jadi nilai rata-rata postest (setelah menggunakan multimedia) lebih besar daripada nilai pretest (sebelum menggunakan multimedia) dengan selisih rata-rata 12,4. Hal ini dapat disimpulkan bahwa terjadi peningkatan nilai hasil belajar siswa setelah digunakannya produk multimedia, sehingga multimedia interaktif tematik Indahnya Negeriku subtema keindahan alam negeriku yang dikembangkan dapat dikatakan efektif.

\section{PEMBAHASAN}

Hasil ujicoba keefektifan produk sejalan dengan beberapa hasil penelitian yang menyatakan bahwa pembelajaran dengan multimedia interaktif (MMSLE) multimedia-mediated student-centred learning environment dapat meningkatkan prestasi belajar, mahasiswa lebih aktif dan termotivasi dalam proses pembelajaran (Leow, 2014). Adapun hasil penelitian sejenis yang menyimpulkan bahwa 
Tabel 2 Rekapitulasi Hasil Analisis Tingkat Kepraktisan, Kemenarikan, dan Efektivitas Penggunaan Multimedia

\begin{tabular}{|c|c|c|c|}
\hline Aspek yang Dinilai & Sasaran Uji Coba & Hasil & Saran / Komentar / Keterangan \\
\hline \multirow[t]{9}{*}{ Kepraktisan $(P 3)$} & Guru $(P 1)$ & Hasil Akhir & 1. Secara keseluruhan media sudah \\
\hline & $82,8 \%$ (Praktis) & $87,15 \% \quad$ (Praktis & bagus. \\
\hline & & dengan revisi kecil) & $\begin{array}{l}\text { 2. Tombol lanjut dan kembali perlu } \\
\text { ditambahkan tulisan agar lebih } \\
\text { jelas. }\end{array}$ \\
\hline & & & $\begin{array}{l}\text { 3. Berikan judul pada setiap materi } \\
\text { pada materi wisata } 1 \text { agar tidak } \\
\text { membingungkan siswa! }\end{array}$ \\
\hline & & & $\begin{array}{l}\text { 4. Jabaran indikator perlu diberi } \\
\text { nomor sesuai dengan KD. }\end{array}$ \\
\hline & Siswa $(P 2)$ & & 1. Pelajaran dengan komputer \\
\hline & 91,5\% (Praktis) & & $\begin{array}{l}\text { sangat menyenangkan dan } \\
\text { mudah dipahami. }\end{array}$ \\
\hline & & & 2. Game bagus dan lebih mudah. \\
\hline & & & $\begin{array}{l}\text { 3. Game perlu ditambahkan lebih } \\
\text { banyak. }\end{array}$ \\
\hline Kemenarikan & Siswa & $92,6 \%$ (Menarik) & - \\
\hline \multirow[t]{5}{*}{ Keefektifan } & Siswa & $\begin{array}{ll}\text { Terdapat } & \text { perbedaan } \\
\text { yang } & \text { signifikan }\end{array}$ & $\begin{array}{l}\text { 1. Dari } 20 \text { siswa, nilai akhir seluruh } \\
\text { siswa tuntas }(\geq 70)\end{array}$ \\
\hline & & $\begin{array}{l}\text { antara nilai pretest } \\
\text { dan postest. }\end{array}$ & $\begin{array}{l}\text { 2. Rata-rata nilai pretest mencapai } \\
\text { nilai } 74,6\end{array}$ \\
\hline & & Kriteria Efektif & $\begin{array}{l}\text { 3. Rata-rata nilai postest mencapai } \\
\text { nilai } 87\end{array}$ \\
\hline & & & 4. $\mathrm{t}_{\text {-hitung }}=-7.566$ \\
\hline & & & 5. $\mathrm{t}_{\text {-tabel }}=-2,093$ \\
\hline
\end{tabular}

terdapat pengaruh penggunaan multimedia sangat signifikan yaitu hasil belajar berdasarkan rata-rata nilai posttest sebesar 81,5 yang bekualifikasi baik, nilaiposttestlebihtinggidariKKM(Febriyan,2014). Berdasarkan hasil analisis yang sudah dipaparkan, dapat dikatakan bahwa hasil uji validasi dan uji coba lapangan, multimedia interaktif indahnya negeriku memiliki kualitas yang tinggi atau layak digunakan dalam pembelajaran di kelas IV SD tema indahnya negeriku subtema keindahan alam negeriku. Multimedia interaktif pada pembelajaran IPS kelas VIII yang dihasilkan dapat dikatakan sudah layak pakai, karena telah dilakukan validasi kepada uji ahli (Pariartha, 2013). Selanjutnya sejalan dengan hasil penelitan menyatakan bahwa multimedia interaktif dikatakan memiliki kualitas yang tinggi jika mencangkup kriteria kevalidan (validity), kepraktisan (practicality), dan keefektifan (effectiveness) (Nieveen, 1999).

Penelitian ini terdapat temuan-temuan selama pembelajaran tematik menggunakan multimedia interaktif, meliputi: (1) multimedia interaktif dapat membantu dan mempermudah guru dalam menyampaikan materi dalam pembelajaran tematik, guru dapat meminimalisir pola pembelajaran konvensional sebagaimana hasil penelitian lain yang menyimpulkan bahwa pembelajaran dengan multimedia interaktif/multimedia tutorial membantu mengatasi keterbatasan pembelajaran yang bersifat tradisional, dan dapat mendorong siswa untuk belajar mandiri (Dalal, 2014); (2) siswa termotivasi dan tertarik sehingga lebih antusias dalam belajar; (3) siswa dapat meningkatkan hasil belajar tematik; (4) siswa memiliki pengetahuan kognitif tentang materi lebih dalam, misalnya siswa mengetahui berbagai keindahan alam yang ada di Indonesia selain keindahan alam di tempat wisata; (5) siswa dapat meningkatkan pengetahuan materi tematik IPS yang berisi kekayaan sumber daya alam, kegiatan perekonomian masyarakat sekitar seperti berbagai pekerjaan di masyarakat, keadaan geografis suatu wilayah, sejarah/asal usul kejadian 
sebuah tempat (misalnya danau Toba); (6) konten materi tematik IPA dan PPKn menunjukkan siswa memiliki keterampilan melalui kegiatan diskusi, praktik percobaan, dan bekerja sama memecahkan permasalahan; (7) konten materi tematik Bahasa Indonesia menunjukkan siswa dapat memiliki keterampilan berbahasa lisan maupun tulis; dan (8) siswa dapat meningkatkan kesadaran terhadap kepedulian lingkungan sebagai wujud rasa syukur terhadap nikmat keindahan alam yang diciptakan Tuhan.

Multimedia interaktif ialah kombinasi berbagai manipulasi digital (teks, gambar, grafik, suara, video, dan animasi) dan elemen interaktif yang dipadukan (Vaughan, 2011; Gunawan, 2016). Interaktif sendiri terkait dengan komunikasi dua arah atau lebih dari komponen-komponen komunikasi (Mishra, 2005). Definisi lain dari multimedia interaktif yaitu media yang digunakan dalam konteks pendidikan yang memadukan kaset video, audio, dan teks yang dikaitkan dengan teknologi seperti CDROM, CD-I (compact disc-interaktif) dan World Wide Web (Collins, 1997). Hadirnya multimedia interaktif tematik ini diharapkan dapat mengakomodir modalitas belajar siswa yang berbeda-beda, pembelajaran menjadi menyenangkan, dan tidak monoton karena menggabungkan elemen gambar, suara, teks, animasi visual, serta sebagai alternatif inovasi pembelajaran. Sebagaimana hasil penelitian yang dilakukan oleh peneliti lain menunjukkan bahwa pembelajaran berbasis multimedia dalam pembelajaran tematik menjadi lebih menyenangkan, mudah, dan tidak membosankan sehingga dapat meningkatkan minat dan motivasi siswa dalam mempelajari tematik (Jusuf, 2009).

Keuntungan multimedia interaktif berdasarkan hasil riset menunjukkan bahwa penggunaan multimedia interaktif lebih efektif dalam pembelajaran daripada menggunakan buku berbasis cetak dan melalui web online (Dikshit, 2013). Lebih lanjut bahwa produk multimedia yang digunakan dalam pembelajaran di kelas IV sekolah dasar berdampak positif bagi prestasi siswa (Arkün, 2008). Hasil-hasil penelitian tersebut dapat dijadikan pijakan bahwa multimedia interaktif perlu diterapkan dalam pembelajaran agar pembelajaran lebih efektif dan hasil belajar siswa dapat ditingkatkan. Hasil penelitian yang mengungkap bahwa multimedia dapat meningkatkan hasil belajar siswa menunjukkan hasil belajar siswa yang dibelajarkan dengan menggunakan media pembelajaran interaktif(kelas eksperimen) lebih tinggi $=33,02$ dari hasil belajar siswa yang dibelajarkan dengan menggunakan media pembelajaran buku teks (kelas kontrol) $=$ 31,11 (Lingin, 2012).

Adanya perbedaan antara kelas eksperimen dan kelas kontrol membuktikan bahwa multimedia interaktif dapat meningkatkan hasil belajar siswa. Berdasarkan hasil temuan-temuan yang sudah dipaparkan. Terdapat temuan bahwa siswa dapat meningkatkan kemampuan tidak hanya dari aspek kognitif, melainkan juga aspek psikomotor dan afektif. Kemampuan yang lebih baik dari segi kognitif dan psikomotorik yaitu siswa yang diajar menggunakan multimedia lebih baik secara teoritis, praktis dan pengetahuan, dan tertarik dengan pembelajaran daripada yang diajar secara konvensional (Milovanoviü, 2013).

\section{KESIMPULAN}

Bertolak dari hasil kajian produk yang telah direvisi dan temuan-temuan penelitian dan pengembangan selama di lapangan dapat disimpulkan sebagai berikut. Produk akhir pengembangan ini adalah CD Multimedia interaktif tematik Indahnya ngeriku yang dilengkapi dengan RPP dan petunjuk penggunaan bagi guru dan siswa. Hasil uji validasi ahli produk multimedia interaktif memperoleh hasil $81,5 \%$ sesuai dengan kriteria sehingga tergolong valid. Validasi multimedia memperoleh masukan kalimat-kalimat yang terlalu panjang dipotong, perlu pemakaian tombol yang konsisten agar lebih beraturan, perlu ditingkatkan keterpaduannya agar saat tombol hyperlink. Hasil Uji coba lapangan antara lain untuk kepraktisan memperoleh hasil $87,15 \%$ sesuai dengan kriteria atau dinilai praktis. Kemenarikan memperoleh hasil 92,6\% sesuai dengan kriteria (menarik). Multimedia Interaktif indahnya negeriku efektif digunakan dalam pembelajaran karena terjadi peningkatan hasil belajar siswa. Hal ini dibuktikan dari nilai rata-rata postest lebih besar daripada nilai pretest. Multimedia interaktif membantu dan mempermudah guru dalam menyampaikan materi dalam pembelajaran tematik. Konten materi tematik dapat meningkatkan keterampilan, sikap, dan pengetahuan siswa. 


\section{DAFTAR RUJUKAN}

Arkün, S. \& Akkoyunlu, B. (2008). A study on the development process of a multimedia learning environment according to the ADDIE model and students' opinions of the multimedia learning environment. Interactive Educational Multimedia, 17, 1-19. Retreived 17 November 2018, from www.ub.es/ multimedia/iem.

Collins, J., Hammond, M., \& Wellington, J. (1997). Teaching and Learning with Multimedia. London: Routledge.

Dalal, M. (2014). Impact of Multimedia Tutorials in a Computer Science Laboratory CourseAn Empirical Study. The Electronic Journal of e-Learning, 12(4).

Daryanto. (2012). Media Pembelajaran. Bandung: Satu Nusa.

Dikshit, J., Garg, S., \& Panda, S. (2013). Pedagogic Effectiveness of Print, Interactive Multimedia, and Online Resources: A Case Study of IGNOU. International Journal of Instruction, 6(2).

Febriyan, I., Santyasa, I. W., \& Tege, I M. (2014). Pengembangan Multimedia Interaktif Berbasis Self Regulated Learning dengan Model ADDIE untuk Meningkatkan Prestasi Belajar Seni Budaya bagi Siswa Kelas VII SMP Negeri 3 Mendoyo. e-Journal Program Pascasarjana Universitas Pendidikan Ganesha, 4(1).

Fogarty, R. (1991). The Mindful School: How To Integrate The Curricula. New York: IRI/ Skylight Publishing.

Gunawan, I. (2016). Manajemen Kelas. Malang: Penerbit UM Press, Universitas Negeri Malang.

Gunawan, I. (2018). Pengembangan Model Pembelajaran Kooperatif Berbasis Lesson Study di Perguruan Tinggi (Upaya Meningkatkan Keaktifan dan Hasil Belajar Peserta Didik). Malang: Universitas Negeri Malang, Penerbit UM Press.

Gunawan, I., \& Sulistyoningrum, R. T. (2013). Menggali Nilai-nilai Keunggulan Lokal Kesenian Reog Ponorogo Guna Mengembangkan Materi Keragaman Suku Bangsa dan Budaya pada Matapelajaran IPS Kelas IV Sekolah Dasar. Premiere
Educandum: Jurnal Pendidikan Dasar dan Pembelajaran, 3(1), 50-87.

Gunawan, I., Wardani, A. D., \& Thohari, A. (2008). Hubungan Penerapan Metode Pembelajaran Kooperatif Model TGT (Teams, Game, and Tournament) Guru Mata Pelajaran Fisika dengan Tingkat Pemahaman dan Motivasi Belajar Siswa SMA Se-Kota Malang. (Unpublished Laporan penelitian), Dirjen Dikti Kemdiknas, Jakarta, Indonesia.

Jusuf, H. (2009). Perancangan Aplikasi Sistem Ajar Tematik Berbasis Multimedia. Jurnal Artificial, ICT Research Center UNAS, 3 (1).

Kusumaningrum, D. E., Arifin, I., \& Gunawan, I. (2017). Pendampingan Pengembangan Perangkat Pembelajaran Berbasis Kurikulum 2013. Abdimas Pedagogi, 1(1), 16-21.

Leow, F. T. (2014). Interactive Multimedia Learning: Innovating Classroom Education in A Malaysian University. TOJET: The Turkish Online Journal of Educational Technology, 13(2).

Lingin, S. S. (2012). Pengembangan Media Pembelajaran Interaktif pada Mata Pelajaran Geografi. Jurnal Teknologi Pendidikan PPS Universitas Negeri Medan, 5(1).

Menteri Pendidikan dan Kebudayaan Republik Indonesia. (2014). Peraturan Pemerintah Nomor 32 Tahun 2013 tentang Perubahan Atas Peraturan Pemerintah Nomor 19 Tahun 2005 Tentang Standar Nasional Pendidikan. 2014. Jakarta: Kemdikbud.

Milovanoviü, M., \& Obradoviü, M. C. J. (2013). Application of Interactive Multimedia Tools in Teaching Mathematics - Examples of Lessons from Geometry. TOJET: The Turkish Online Journal of Educational Technology, 12(1), 19-31.

Mishra, S., \& Ramesh, C. S. (2005). Interactive Multimedia in Education and Training. United States of America: Idea Group Publishing (an imprint of Idea Group Inc.).

Mursidik, E. M., Tryanasari, D., \& Gunawan, I. (2013). Pengembangan Buku Pedoman Microteaching Berbasis Lesson Study Prodi PGSD FIP IKIP PGRI MADIUN. Jurnal Pendidikan, 19(1), 1-26.

Nieveen, N. (1999). Prototyping to reach product quality. In Design approaches and tools 
in education and training (pp. 125-135).

Springer, Dordrecht.

Pariartha, G. M. A., Parmiti, D. P., \& Sudatha, I. G. W. (2013). Pengembangan Media Pembelajaran Berbasis Multimedia Interaktif pada Mata Pelajaran IPA untuk Siswa Kelas VIII Semester 1 Di SMP Negeri 3 Singaraja Tahun Pelajaran 2012/2013. Jurnal Pendidikan Undiksha, 1(2).

Prastowo, A. (2013). Pengembangan Bahan Ajar Tematik Panduan Lengkap Aplikatif. Yogyakarta: Diva Press.

Smaldino, S. E., Lowther, D. L., \& Russell, J. D. (2008). Teknologi Pembelajaran dan Media untuk Belajar. Terjemahan oleh Arif Rahman. 2011. Jakarta: Kencana Prenada Media Group.

Sugiyono. (2010). Metode Penelitian Pendidikan Pendekatan Kuantitatif Kualitatif, dan $R$ dan $D$. Bandung: Alfabeta.

Vaughan, T. (2011). Multimedia: Making it Work Eighth Edition. New York: McGraw-Hill Companies Inc. 